\title{
RESEARCH
}

Open Access

\section{Antibiotic prescription for under-fives with common cold or upper respiratory tract infection in Savannakhet Province, Lao PDR}

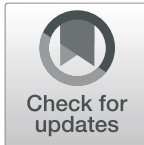

Bounxou Keohavong ${ }^{1,2}$, Manithong Vonglokham³ ${ }^{3}$ Bounfeng Phoummalaysith ${ }^{4}$, Viengsakhone Louangpradith ${ }^{1,5}$, Souphalak Inthaphatha', Tetsuyoshi Kariya', Yu Mon Saw', Eiko Yamamoto ${ }^{1}$ and Nobuyuki Hamajima ${ }^{1 *}$

\begin{abstract}
Background: The irrational use of antibiotics has been identified as a major problem in healthcare, and it can lead to antimicrobial resistance, treatment failure, and increased healthcare costs. Although many studies worldwide have focused on the irrational use of drugs, reports on prescription practice in Lao PDR remained limited. This study aimed to examine the patterns of antibiotic prescription for under-fives with common cold or upper respiratory tract infection (URTI) at pediatric outpatient divisions.

Methods: One provincial hospital (PH) at Kaisone Phomvihane and four district hospitals (DHs) at Songkhone, Champhone, Atsaphangthong, and Xepon in Savannakhet Province were selected. Healthcare providers at these hospitals were interviewed and medical records of under-fives from 2016 were examined.

Results: Of the 54 healthcare providers interviewed, $85.2 \%$ had seen the standard treatment guideline, $77.8 \%$ adhered to this guideline, and $90.7 \%$ knew about antimicrobial resistance, while $18.5 \%$ participated in antimicrobial resistance activities. Medical records of 576 outpatients (311 boys and 265 girls) with common cold or URTI were examined, 154 at the $\mathrm{PH}$ and 422 at the DHs. Although antibiotics prescription proportions were similar between facilities at both levels (68.8\% and $70.9 \%$ at the PH and DHs, respectively), antibiotics were exclusively prescribed for URTIs (96.4\%), not for common cold (4.9\%). First-line antibiotics recommended by WHO Model List of Essential Medicines for Children the 6th List were prescribed for $81.5 \%$ of patients; mainly, beta-lactam antibiotics were prescribed $(87.2 \%$ of prescribed antibiotics). There were no cases in which two or more antibiotics were prescribed. The correct dose according to the National STG was 31.9\% as a whole. The difference in the correct dose between the PH (52.8\%) and the DHs (24.4\%) was significant $(p<0.001)$.

Conclusions: This study demonstrated the patterns of antibiotic prescription for under-fives with common cold or URTI among healthcare providers from two different levels of facilities. Although an appropriate number of generic first-line antibiotics in the essential drug list were prescribed, the dosage and duration of antibiotic use were not appropriate. In order to further improve antibiotic prescription practices, regulation by the government is necessary; this could also decrease antimicrobial resistance and improve treatment outcomes.
\end{abstract}

Keywords: Prescribing practice, Antibiotics, Common cold, Upper respiratory tract infections, Lao PDR

\footnotetext{
* Correspondence: nhamajim@med.nagoya-u.ac.jp

'Department of Healthcare Administration, Nagoya University Graduate

School of Medicine, 65 Tsurumai-Cho, Showa-Ku, Nagoya 466-8550, Japan

Full list of author information is available at the end of the article
}

(c) The Author(s). 2019 Open Access This article is distributed under the terms of the Creative Commons Attribution 4.0 International License (http://creativecommons.org/licenses/by/4.0/), which permits unrestricted use, distribution, and reproduction in any medium, provided you give appropriate credit to the original author(s) and the source, provide a link to the Creative Commons license, and indicate if changes were made. The Creative Commons Public Domain Dedication waiver (http://creativecommons.org/publicdomain/zero/1.0/) applies to the data made available in this article, unless otherwise stated. 


\section{Introduction}

Mortality from infectious diseases is a major health issue, especially among children. The appropriate use of antibiotics is critical for pediatric medical care. Upper respiratory tract infections (URTIs) are commonly observed among children under 5 years of age (U5) for whom antibiotics have been frequently prescribed. Self-medication with antibiotics is also commonly observed in many developing countries, and unnecessary medication and inappropriate antibiotic use can lead to antimicrobial resistance, treatment failure, and increased healthcare costs [1-4]. Thus, healthcare providers need to pay close attention to inappropriate antibiotic prescription $[5,6]$, and policy makers should develop efficient strategies to reduce such inappropriate prescriptions [7].

Several studies on community antibiotic use have been performed in high-income countries $[8,9]$. Among the developing countries, antibiotic overprescription has been reported in Pakistan and India, as well as in several African countries [10,11]. The overuse of drugs, linked to inappropriate prescription practices, may increase health cost budgets in countries aiming for universal health coverage.

Studies addressing this issue in Lao People's Democratic Republic (Lao PDR) are limited. Available studies have revealed the prevalence of inappropriate antibiotic use practices in private pharmacies in Lao PDR [12-14]. The irrational use of medicines is frequently observed in developing countries. In Lao PDR, unnecessary antibiotic prescriptions were found to be frequent; the 2016 annual report on the treatment of tracer diseases in four northern provinces revealed that $70 \%$ of U5 with usual diarrhea received antibiotics on visiting an outpatient division (OPD). A survey of prescribers and prescriptions in Lao PDR revealed the considerable use of polypharmacy and overuse of antibiotics [13].

Lao PDR showed substantial progress in decreasing the mortality rate among U5, achieving Millennium Development Goal 4 in 2015 [15]. The U5 mortality declined from 163 per 1000 in 1990 to 70 per 1000 in 2012 [16]. During this period, under the National Drug Policy Programme, the Ministry of Health $(\mathrm{MoH})$, Lao PDR recommended all provincial and district hospitals to establish their own drug and therapeutics committee (DTC). In addition, indicators to evaluate DTC performance and Standard Treatment Guideline (STG) use were developed for measuring the quality of treatment, rational use of drugs (RUD) during prescription, and better hospital management [17]. This study aimed to examine knowledge and practices, as well as the practices related to antibiotic prescription for U5 with common cold or URTI in pediatric OPDs in Savannakhet Province.

\section{Materials and methods \\ Participants}

Savannakhet is the largest $\left(21,774 \mathrm{~km}^{2}\right)$ and most populous province of Lao PDR, with 1,001,000 inhabitants (512,000 males and 489,000 females) in 2017. Savannakhet has 15 districts. Among those, one district (Kaisone Phomvihane) has a tertiary provincial hospital (PH) and four districts (Songkhone, Champhone, Atsaphangthong, and Xepon) have one secondary district hospitals (DHs) each. The remaining ten districts have no tertiary/secondary hospitals [18].

Healthcare providers were selected through convenient sampling among medical staff at pediatric OPDs providing healthcare for U5 at the $\mathrm{PH}$ and four DHs. They were aged 22 to 57 years, and their experience as healthcare providers ranged from 2 months to 36 years. Interviews were conducted by two researchers. U5 outpatients diagnosed with common cold or URTI were sampled from the list of outpatients who visited the hospitals during the first week (five consecutive days, Monday to Friday) of each month in 2016 (in total 60 days). Common cold was defined as symptoms of inflammation in the nose and throat mucous membrane with body temperature exceeding $37^{\circ} \mathrm{C}$, but without a sore throat. URTI including pharyngitis, otitis media, and tonsillitis was defined as the presence of a sore throat, difficulty in swallowing, red throat, white particles in the throat, and/or earaches, with a body temperature exceeding $37^{\circ} \mathrm{C}$, and white blood cell counts of more than 9000 cells $/ \mu \mathrm{l}$.

\section{Questionnaire}

The questionnaire administered to healthcare providers consisted of four main items: (1) characteristics of the interviewee, (2) knowledge about prescription, (3) prescription practice and expectation on prescription, and (4) belief in antibiotic prescription practice. The questionnaire was pretested at Vientiane Provincial Hospital. The above information was collected with a face-to-face interview using the questionnaire during 25-30 min per interviewee.

Information of U5 outpatients was collected using a data form from medical charts. This included information on (1) sex, (2) age, (3) health insurance scheme, (4) diagnosis, (5) number of prescribed drugs, (6) number of prescribed antibiotics, (7) drug name, (8) examination and tests before diagnosis, and (9) rationale of prescription practice based on the STG recommendations.

\section{Standard treatment guideline in Lao PDR}

The first version of the National STG was developed in 1998, with funding from the Swedish International Development Agency. The Healthcare Department in cooperation with the Food and Drug Department of $\mathrm{MoH}$ was responsible for developing the National STG. 
Since the healthcare providers in Lao PDR were graduates from medical schools in domestic and foreign countries, their knowledge and practice were based on different standards. The first version of the National STG was developed for seven selected leading causes of morbidity and mortality in Lao PDR (malaria, diarrhea, upper and lower respiratory tract infection, tuberculosis, dengue, leprosy, and parasite infections). It was revised to address 16 diseases including common cold, with the latest revision (2012) addressing 255 diseases [19]. The National STG is distributed among all levels of health facilities in Lao PDR. It has been used by healthcare providers as a reference for treatment and prescription. The recent STG for URTI recommends a 10-day regime consisting of (1) penicillin V 50,000-100,000 UI/kg/day, four times daily, (2) erythromycin $40 \mathrm{mg} / \mathrm{kg} /$ day, four times daily in cases of allergy to penicillin $\mathrm{V}$, or (3) amoxicillin $30-50 \mathrm{mg} / \mathrm{kg} /$ day, three times daily, as well as antipyretic (paracetamol) medication and recommendations for sufficient water and food intake and relaxation.

\section{Statistical analysis}

CSPro version 7.1 was used for data entry, and IBM Statistical Package for Social Sciences (SPSS) version 20 was used for statistical analysis. Categorical data were examined using a chi-square test. The $95 \%$ confidence interval (CI) of the percentage was calculated using the binomial distribution. An unconditional logistic model was applied to estimate odds ratios (ORs) and their 95\% CIs. A $p$ value less than 0.05 was considered statistically significant.

\section{Results}

\section{Usage of the guidelines}

In total, 54 healthcare providers $(20$ males and 34 females) at five health facilities (6 at one $\mathrm{PH}$ and 48 at four DHs) were interviewed. These individuals were the staff involved in medical check-ups at outpatient wards; $22(40.7 \%)$ medical doctors, 4 (7.4\%) pediatricians, 11 (20.4\%) general practitioner, and 17 (31.5\%) primary healthcare staff (Table 1). A bachelor's degree was the most common qualification (35.2\%) among the interviewees, followed by medical assistant (16.7\%). Further, $11.1 \%$ were medical specialist level 1 , healthcare providers with an additional specialization in a certain medical field with 3 -year post graduation training. Forty (74.1\%) interviewees were permanent employees, while 13 (24.1\%) were volunteers. One third of the healthcare providers worked at outpatient wards, and the rest worked in emergency units and inpatient wards. All of them had been providing healthcare services to U5 at public health facilities; half of them had been providing
Table 1 Characteristics of healthcare providers interviewed

\begin{tabular}{llll}
\hline Characteristics & Male & Female & Total \\
& $N(\%)$ & $N(\%)$ & $N(\%)$ \\
\hline Healthcare providers interviewed & $20(100)$ & $34(100)$ & $54(100)$ \\
Facility & & & \\
Provincial hospital & $1(5.0)$ & $5(14.7)$ & $6(11.1)$ \\
District hospitals & $19(95.0)$ & $29(85.3)$ & $48(88.9)$ \\
Medical background & & & \\
Medical doctors & $12(60.0)$ & $10(29.4)$ & $22(40.7)$ \\
Pediatricians & $1(5.0)$ & $3(8.8)$ & $4(7.4)$ \\
General practitioners ${ }^{\mathrm{a}}$ & $1(5.0)$ & $10(29.4)$ & $11(20.4)$ \\
Primary healthcare staff ${ }^{\mathrm{b}}$ & $6(30.0)$ & $11(32.4)$ & $17(31.5)$ \\
Professional level & & & \\
Master degree & $0(0.0)$ & $1(2.9)$ & $1(1.9)$ \\
Bachelor & $9(45.0)$ & $10(29.4)$ & $19(35.2)$ \\
Specialist level ${ }^{c}$ & $3(15.0)$ & $3(8.8)$ & $6(11.1)$ \\
Medical assistant & $2(10.0)$ & $7(20.6)$ & $9(16.7)$ \\
Other & $6(30.0)$ & $13(38.2)$ & $19(35.2)$ \\
Employee status & & & \\
Employed & $12(60.0)$ & $28(82.4)$ & $40(74.1)$ \\
Work contact & $0(0.0)$ & $1(2.9)$ & $1(1.9)$ \\
Voluntary staff & $8(40.0)$ & $5(14.7)$ & $13(24.1)$ \\
Working division & & & \\
OPD & $9(20.0)$ & $11(32.4)$ & $15(27.8)$ \\
IPD & $9(35.0)$ & $9(26.5)$ & $18(33.3)$ \\
Emergency department & $14(41.2)$ & $21(38.9)$ \\
Herk experiences/practice & & & \\
Heath check-up for U5 & & $17(50.0)$ & $28(51.9)$ \\
\hline
\end{tabular}

${ }^{\mathrm{a} G e n e r a l ~ m e d i c a l ~ s t a f f ~ w i t h ~ a ~ b a c h e l o r ~ d e g r e e ~ g r a d u a t e d ~ f r o m ~ a ~}$ medical school

${ }^{\mathrm{b}}$ Staff graduated from 2-year primary healthcare school

'Staff with additional specialization after a 3-year training

$H F$ health facility, OPD outpatient division, IPD inpatient division, U5 children under 5 years of age

healthcare services to U5 at a private health facility as a part-time job (51.9\%).

Table 2 shows the knowledge of the healthcare providers according to sex. Most providers had seen the STG for children $(98.1 \%, 95 \%$ CI 90.1-99.9\%), and applied it for the prescription $(96.3 \%$, 95\% CI 87.2-99.5\%). Further, 87.0\% (95\% CI 75.1-94.6\%) had heard about DTC, only $22.2 \%$ were DTC members, and $61.1 \%$ (95\% CI $46.9-74.1 \%$ ) had contributed to the DTC's activities in their own health facilities. Among the 54 healthcare providers, $72.2 \%$ (95\% CI 58.4-83.5\%) had seen the essential drug list (EDL), 92.6\% (95\% CI 82.1-97.9\%) had heard about adverse drug reactions (ADR), and 90.7\% (95\% CI 79.7-96.9\%) had heard about antimicrobial resistance. Moreover, 44.4\% (95\% CI 30.9-58.6\%) had heard about the Antibiotic Awareness 
Table 2 Knowledge of healthcare providers (20 males and 34 females): those who answered "yes" to each question

\begin{tabular}{|c|c|c|c|}
\hline \multirow[t]{2}{*}{ Question } & Male & Female & Total \\
\hline & $N(\%)$ & $N(\%)$ & $N(\%)$ \\
\hline Have ever seen main STG & $18(90.0)$ & $28(82.4)$ & $46(85.2)$ \\
\hline Have ever seen STG for children & $19(95.0)$ & $34(100.0)$ & $53(98.1)$ \\
\hline Using main STG in prescribing medicines & $15(75.0)$ & $27(79.4)$ & $42(77.8)$ \\
\hline Using STG for children in prescribing medicines & $20(100.0)$ & $32(94.1)$ & $52(96.3)$ \\
\hline Have ever heard about DTC & $17(85.0)$ & $30(88.2)$ & $47(87.0)$ \\
\hline Member of the DTC & $4(20.0)$ & $8(23.5)$ & $12(22.2)$ \\
\hline Have ever been contributed to DTC performance & $10(50.0)$ & $23(67.6)$ & $33(61.1)$ \\
\hline Have ever seen EDL & $13(65.0)$ & $26(76.5)$ & $39(72.2)$ \\
\hline Have ever heard about ADR & $18(90.0)$ & $32(94.1)$ & $50(92.6)$ \\
\hline Have contribute to ADR reporting & $3(15.0)$ & $11(32.4)$ & $14(25.9)$ \\
\hline Have ever heard about AAW & $10(50.0)$ & $14(41.2)$ & $24(44.4)$ \\
\hline Have been joined AAW activity & $4(20.0)$ & $6(17.6)$ & $10(18.5)$ \\
\hline Have ever heard about antimicrobial resistant & $18(90.0)$ & $31(91.2)$ & $49(90.7)$ \\
\hline Have ever been trained on medical practice & $18(90.0)$ & $28(82.4)$ & $46(85.2)$ \\
\hline Have ever been trained RUD* & $13(65.0)$ & $12(35.3)$ & $25(46.3$ \\
\hline
\end{tabular}

STG standard treatment guideline, DTC drug and therapeutics committee, EDL essential drug list, $A D R$ adverse drug reaction, $A A W$ Antibiotic Awareness Week, $R U D$ rational use of drugs,

${ }^{*} p<0.05$ between males and females

Week (AAW), and 18.5\% (95\% CI 9.2-31.4\%) had participated in AAW activities at least once. Approximately seven eighths of them had been trained in medical practice in the last 2 years $(85.2 \%, 95 \%$ CI $72.9-93.4 \%)$, but less than half had received RUD training (46.3\%, 95\% CI 32.6-60.4\%).
The percentage was significantly higher among males (65.0\%, 95\% CI 40.8-84.6\%) than among females (35.3\%, 95\% CI $19.7-53.5 \%)$.

Table 3 shows the prescription practices and expectation on prescription among the 54 healthcare providers.

Table 3 Prescription practices and expectation on prescription among healthcare providers (20 males and 34 females)

\begin{tabular}{|c|c|c|c|}
\hline & Male & Female & Total \\
\hline & $N(\%)$ & $N(\%)$ & $N(\%)$ \\
\hline \multicolumn{4}{|l|}{ Laboratory examination } \\
\hline Blood test for every case & $2(10.0)$ & $1(2.9)$ & $3(5.6)$ \\
\hline Blood testing for selected cases & $17(85.0)$ & $30(88.2)$ & $47(87.0)$ \\
\hline Based on symptoms & $20(100.0)$ & $34(100.0)$ & $54(100.0)$ \\
\hline Based on full examination & $16(80.0)$ & $24(70.6)$ & $40(74.1)$ \\
\hline In case of an enough time available & $15(75.0)$ & $30(88.2)$ & $45(83.3)$ \\
\hline \multicolumn{4}{|l|}{ Reason for $A B$ prescription } \\
\hline Base on observed symptoms & $20(100.0)$ & $33(97.1)$ & $53(98.1)$ \\
\hline Just for prevention & $2(10.0)$ & $0(0.0)$ & $2(3.7)$ \\
\hline Based on experiences & $5(25.0)$ & $5(14.7)$ & $10(18.5)$ \\
\hline \multicolumn{4}{|l|}{ Expectation from prescribing practice } \\
\hline Being confident for $A B$ prescription & $20(100.0)$ & $30(88.2)$ & $50(92.6)$ \\
\hline Have concerns about quality of $A B$ prescribed & $17(85.0)$ & $22(64.7)$ & $39(72.2)$ \\
\hline Have concerns about compliance to the advice & $18(90.0)$ & $25(73.5)$ & $43(79.6)$ \\
\hline Have concerns about self-medication of $A B$ & $18(90.0)$ & $28(82.4)$ & $46(85.2)$ \\
\hline Have concerns about $A B$ resistant & $19(95.0)$ & $30(88.2)$ & $49(90.7)$ \\
\hline Have concerns about adverse effects and resistance & $20(100.0)$ & $29(85.3)$ & $49(90.7)$ \\
\hline
\end{tabular}


In all, 5.6\% (95\% CI 1.2-15.4\%) stated that they performed blood tests for every outpatient. Antibiotics were prescribed by relying on symptoms in $98.1 \%$ (95\% IC 90.1-99.9\%) of cases. Although 92.6\% (95\% CI 82.1$97.9 \%$ ) of providers reported having confidence in the prescription, $72.2 \%$ (95\% CI 58.4-83.5\%) had concerns about the quality of antibiotics, $79.6 \%$ had concerns about patients following their advice, 85.2\% (95\% CI 72.9-93.4\%) had concerns about self-medication of antibiotics at the next occurrence of similar symptoms, and $90.7 \%$ (95\% CI 79.7-96.9\%) had concerns about the adverse effects of antibiotics and antimicrobial resistance. While almost all healthcare providers believed in treatment guidelines (98.1\%, 95\% CI 90.1-99.9\%), 61.1\% (95\% CI 46.9-74.1\%) strongly agreed with the effectiveness of the regulation, and $64.8 \%$ (95\% CI 50.6-77.3\%) believed in the prioritizing careful examination (Table 4).

\section{Antibiotic prescription based on medical records}

Information on antibiotic prescription was collected for 576 children (311 boys and 265 girls) who were diagnosed with common cold or URTI in 2016 at the OPD of Savannakhet PH (154 patients) and four DHs (422 patients). Among U5, the 1-year age group was the largest (25.2\%, 95\% CI 21.7-28.9\%), while the 4-year age group was the smallest $(12.3 \%$, 95\% CI 9.8-15.3\%), as shown in Table 5. Further, 39.4\% (95\% CI 35.4-43.5\%) of the patients were not covered by health insurance. Approximately $70 \%$ of the 349 insured patients were covered by community-based health insurance. Moreover, $31.2 \%$ (95\% CI $24.0-39.1 \%$ ) and $27.5 \%$ (95\% CI 23.3-32.0\%) were diagnosed with common cold at the $\mathrm{PH}$ and the DHs, respectively.

Table 6 shows the number of drug items prescribed for U5. On average, 2.4 drug items (375 items) were prescribed for 154 outpatients at the $\mathrm{PH}$, and 2.8 drug items (1166 items) were prescribed for 422 outpatients at the DHs. At the $\mathrm{PH}$, essential drugs were prescribed for 83.4\% (95\% CI 79.3-87.1\%) of U5 patients, and $77.6 \%$ (95\% CI 73.0-81.7\%) were prescribed drugs using a generic name (international non-proprietary name; INN). Antibiotics were prescribed for 106 (68.8\%, 95\% CI 60.9-76.0\%) patients, and nobody was prescribed more than one antibiotic. First-line antibiotics (amoxicillin, ampicillin, erythromycin, and penicillin V) were prescribed for $97.2 \%$ (95\% CI 91.9-99.4\%) of patients. Moreover, beta-lactam antibiotics were prescribed for 87.7\% (95\% CI 79.4-93.3\%), while macrolides were prescribed for $9.4 \%$ (95\% CI 4.6-16.7\%). Among the 1166 drugs at the DHs, $91.5 \%$ (95\% CI 89.9-93.1\%) were from EDL, and 81.7\% (95\% CI 79.4-83.9\%) were generic drugs. Antibiotics were prescribed for 299 (70.9\%, 95\% CI 66.3-75.1\%) patients. Even at the DHs, nobody was prescribed more than one antibiotic. First-line antibiotics

Table 4 Belief in antibiotic prescription practices among healthcare providers (20 males and 34 females)

\begin{tabular}{|c|c|c|c|}
\hline \multirow[t]{2}{*}{ Belief } & Male & Female & Total \\
\hline & $N(\%)$ & $N(\%)$ & $N(\%)$ \\
\hline \multicolumn{4}{|c|}{ What is the most important to contribute effective $A B$ prescription } \\
\hline Following the guidelines & $20(100.0)$ & $33(97.1)$ & $53(98.1)$ \\
\hline Full examination before prescription & $20(100.0)$ & $32(94.1)$ & $52(96.3)$ \\
\hline Ethical prescription & $19(95.0)$ & $33(97.1)$ & $52(96.3)$ \\
\hline \multicolumn{4}{|c|}{ Do you agree that $A B$ prescription regulation can change prescribers' behaviour to better prescription practices } \\
\hline Strongly agree & $12(60.0)$ & $21(61.8)$ & $33(61.1)$ \\
\hline Agree & $5(25.0)$ & $8(23.5)$ & $13(24.1)$ \\
\hline Not sure & $3(15.0)$ & $5(14.7)$ & $8(14.8)$ \\
\hline \multicolumn{4}{|c|}{ The priority message to prescribers on $A B$ prescription } \\
\hline Careful examination & $12(60.0)$ & $23(67.6)$ & $35(64.8)$ \\
\hline Avoidance of $A B$ prescription if possible & $3(15.0)$ & $5(14.7)$ & $8(14.8)$ \\
\hline Full laboratory examine & $2(10.0)$ & $3(8.8)$ & $5(9.3)$ \\
\hline Practices based on guidelines & $3(15.0)$ & $1(2.9)$ & $4(7.4)$ \\
\hline Prescription of first-line $A B$ if necessary & $0(0.0)$ & $2(5.9)$ & $2(3.7)$ \\
\hline \multicolumn{4}{|c|}{ The priority message for health policy makers to act on AB prescription practice improvement } \\
\hline Development of $A B$ prescription regulation & $12(60.0)$ & $16(47.1)$ & $28(51.9)$ \\
\hline Advocacy to related health staff & $3(15.0)$ & $7(20.6)$ & $10(18.5)$ \\
\hline Strong promotion of RUD & $3(15.0)$ & $6(17.6)$ & $9(16.7)$ \\
\hline Awards for good prescribers & $1(5.0)$ & $3(8.8)$ & $4(7.4)$ \\
\hline
\end{tabular}

$A B$ antibiotics, $R U D$ rational use of drugs 
Table 5 Characteristics of outpatients under 5 years of age at provincial hospital $(\mathrm{PH})$ and district hospitals $(\mathrm{DH})$

\begin{tabular}{|c|c|c|c|}
\hline \multirow[t]{2}{*}{ Characteristics } & $\mathrm{PH}$ & $\mathrm{DH}$ & Total \\
\hline & $N(\%)$ & $N(\%)$ & $N(\%)$ \\
\hline Total & $154(100)$ & $422(100)$ & $576(100)$ \\
\hline Boys & $74(48.1)$ & $237(56.2)$ & $311(54.0)$ \\
\hline Girls & $80(51.9)$ & $185(43.8)$ & $265(46.0)$ \\
\hline \multicolumn{4}{|l|}{ Age group } \\
\hline 0 year & $29(18.8)$ & $98(23.2)$ & $127(22.0)$ \\
\hline 1 year & $31(20.1)$ & $114(27.0)$ & $145(25.2)$ \\
\hline 2 years & $42(27.3)$ & $93(22.0)$ & $135(23.4)$ \\
\hline 3 years & $34(22.1)$ & $64(15.2)$ & $98(17.0)$ \\
\hline 4 years & $18(11.7)$ & $53(12.6)$ & $71(12.3)$ \\
\hline \multicolumn{4}{|l|}{ Health insurances status } \\
\hline Covered by health insurance & $90(58.4)$ & $259(61.4)$ & $349(60.6)$ \\
\hline SASS* & $22(14.3)$ & $24(5.7)$ & $46(8.0)$ \\
\hline $\mathrm{SSO}^{* *}$ & $31(20.1)$ & $14(3.3)$ & $45(7.8)$ \\
\hline$\left.\mathrm{CBH}\right|^{* *}$ & $37(24.0)$ & $201(47.6)$ & $238(41.3)$ \\
\hline $\mathrm{HEF}^{*}$ & $0(0.0)$ & $21(5.0)$ & $21(3.6)$ \\
\hline Not covered by health insurance & $64(41.6)$ & $163(38.6)$ & $227(39.4)$ \\
\hline \multicolumn{4}{|l|}{ Symptomatic of outpatient } \\
\hline Common cold & $48(31.2)$ & $116(27.5)$ & $164(28.5)$ \\
\hline Pharyngitis & $92(59.7)$ & $26(62.3)$ & 355 (61.6) \\
\hline Otitis media & $0(0.0)$ & $7(1.7)$ & $7(1.2)$ \\
\hline Tonsilitis/amygdalite & $14(9.1)$ & $36(8.5)$ & $50(8.7)$ \\
\hline
\end{tabular}

SASS state authority for social security, SSO social security organization, $C B H I$ community-based health insurance, HEF health equity fund ${ }^{*} p<0.01$

${ }^{* *} p<0.001$ between $\mathrm{PH}$ and $\mathrm{DH}$

were prescribed for $97.7 \%$ of the U5. The beta-lactams, macrolides, and cephalosporins were prescribed $87.0 \%$ (95\% CI $82.6-90.6 \%), 11.0 \%$ (95\% CI 7.7-15.1\%), and $1.7 \%$ (95\% CI $0.5-3.9 \%$ ), respectively. Among the first-line antibiotics, $87.7 \%$ (95\% CI 79.9-93.3\%) and 79.3\% (95\% CI 74.2-83.7\%) at the $\mathrm{PH}$ and DHs, respectively, were recommended by WHO Model List of Essential Medicines for Children the 6th List. The correct dose based on the National STG was administered to $52.8 \%(95 \%$ CI $42.9-62.6 \%)$ at the $\mathrm{PH}$ and $24.4 \%$ (95\% CI 19.7-29.7\%) at the DHs, and the appropriate duration was prescribed for $2.2 \%$ (95\% CI 1.0-4.2\%) of U5.

Table 7 shows the ORs and 95\% CIs of antibiotic prescription for U5 with common cold or URTI. Antibiotics were prescribed for eight (4.9\%) out of 164 patients with common cold, 341 (96.0\%) out of 355 patients with pharyngitis, and 56 (98.3\%) out of 58 patients with other URTI. After adjustment, factors other than diagnosis were not significantly associated with antibiotic prescription.

\section{Discussion}

\section{Usage of the guideline}

This study demonstrated a high usage of the National STG (77.8\%), especially for children (96.3\%). The guideline was designed to be convenient for healthcare providers. The usage in our study was higher than that in Ghana (41.7\%) [20], South Africa (45.1\%) [21], and Israel (55.7\%) [22]. Most healthcare providers had heard about DTC (87.0\%), but only $22.2 \%$ were DTC members. Although the EDL had been distributed among all levels of health facilities, the current study found that $72.2 \%$ of the interviewees confirmed having seen this list, which was meant to be used as a reference for the procurement and prescription. Most interviewees stated that they had heard about ADR (92.6\%) and antimicrobial resistance (90.7\%), possibly because Lao PDR became an official member of the WHO Uppsala Monitoring Center in July 2015, due to which the interviewees gained information about these topics. Antimicrobial resistance is a great public health concern [23] and has become an important issue that needs to be addressed at all health sector levels. WHO urged all member countries to strongly promote measures for preventing antimicrobial resistance. There was a significantly higher proportion of healthcare providers with experience in RUD training among males (65.0\%) than among females (35.3\%). Since RUD trainings were usually held at a provincial level, far from the residency for most interviewees, women might have hesitated to participate. To change prescription practices, training opportunities should be increased [24].

More than $70 \%$ of interviewees had concerns about the quality of antibiotics. A survey on the quality of drugs conducted in 2012 revealed that the quality of drugs in Lao PDR, especially antimalarial drugs, was not well controlled [25]. Self-medication with antibiotics is also a great concern in Lao PDR. In our study, $85.2 \%$ of healthcare providers had concerns about self-medication. A study demonstrated that $55.5 \%$ of people with mild diseases in a peri-urban area were self-medicated at home [26].

Almost all interviewees (98.1\%) stated that compliance with the guidelines would contribute to more appropriate antibiotic prescriptions. In addition, $61.1 \%$ of them strongly agreed that regulation is effective for RUD. Regulations for antibiotic prescription are important for improving prescription practices [27]. Policy makers should consider developing antibiotic prescription regulations.

Since there were only six healthcare providers at the $\mathrm{PH}$, a comparison of responses between interviewees from the $\mathrm{PH}$ and the $\mathrm{DHs}$ did not seem meaningful. Another limitation of the survey among healthcare providers was that the subjects were the employees who voluntarily participated in this interview. In addition, the information was obtained through interviews rather than 
Table 6 Drug prescriptions for outpatients under 5 years of age at provincial hospital (PH) and district hospitals (DH)

\begin{tabular}{|c|c|c|c|}
\hline \multirow[t]{2}{*}{ Variables } & $\mathrm{PH}$ & $\mathrm{DH}$ & Total \\
\hline & $N(\%)$ & $N(\%)$ & $N(\%)$ \\
\hline All prescribed drugs & $375(100)$ & $1166(100)$ & $1541(100)$ \\
\hline EDL drugs & $313(83.4)$ & $1068(91.5)$ & $1381(89.6)$ \\
\hline INN drugs & $291(77.6)$ & $953(81.7)$ & $1244(80.7)$ \\
\hline$A B$ medication & $106(100)$ & $299(100)$ & $405(100)$ \\
\hline First-line antibiotics based on National STG & $103(97.2)$ & $292(97.7)$ & $395(97.5)$ \\
\hline Drugs other than the first-line antibiotics & $3(2.8)$ & $7(2.3)$ & $10(2.5)$ \\
\hline More than one antibiotic & $0(0.0)$ & $0(0.0)$ & $0(0.0)$ \\
\hline \multicolumn{4}{|l|}{ Antibiotic family } \\
\hline Beta-lactams & $93(87.7)$ & $260(87.0)$ & $353(87.2)$ \\
\hline Cephalosporins & $2(1.9)$ & $5(1.7)$ & $7(1.7)$ \\
\hline Macrolides & $10(9.4)$ & $33(11.0)$ & $43(10.6)$ \\
\hline Sulfonamides & $1(0.9)$ & $1(0.3)$ & $2(0.5)$ \\
\hline \multicolumn{4}{|l|}{$A B$ prescription } \\
\hline First-line AB based on WHO MLEMC & $93(87.7)$ & $237(79.3)$ & $330(81.5)$ \\
\hline Correct doses based on the National STG* & $56(52.8)$ & $73(24.4)$ & $129(31.9)$ \\
\hline Appropriate duration based on the National STG & $0(0.0)$ & $9(3.0)$ & $9(2.2)$ \\
\hline
\end{tabular}

WHO MLEMC: WHO Model List of Essential Medicines for Children the 6th List (March 2017). First-line antibiotics of the National STG include amoxicillin, ampicillin, erythromycin, and penicillin V. The first-line antibiotics based on the WHO MLEMC includes amoxicillin and penicillin $\mathrm{V}$

$A B$ antibiotics, $E D L$ essential drug list, INN international non-proprietary name, SD standard deviation, STG standard treatment guideline

${ }^{*} p<0.001$ between $\mathrm{PH}$ and $\mathrm{DH}$

from objective records, which might have led to some inaccuracy.

\section{Actual antibiotic prescription based on medical records}

Several factors may influence antibiotic prescription. Although data on this was not available in this study, requests from family members could be a strong contributor $[28,29]$. Accurate diagnosis of viral or bacterial infection is also important for appropriate antibiotic use, but reliable diagnostic techniques are not widely available in Lao PDR. Patients were diagnosed based on their symptoms and limited laboratory tests. Without laboratory tests, it is difficult to rule out viral infections from URTI [30].

On average, 2.4 drug items were prescribed at the $\mathrm{PH}$ and 2.8 drug items were prescribed at the DHs. Although the average was slightly higher than the WHO reference value ( 2 items per visit), it was similar to values found in studies of the WHO African region (2.4 to 3.5 items) [31] and relatively higher than values noted in Ethiopia (1.9 items) [32]. Antibiotics were prescribed for $68.8 \%(106 / 154)$ of patients at the $\mathrm{PH}$ and $70.9 \%$ $(299 / 422)$ at the DHs.

This study found that drugs on the EDL were frequently used (83.4\%). The use of generic drugs was $80.7 \%$, which is higher than the rate reported in a 2012 survey demonstrating that the majority of doctors (55.2\%) prescribed generic antibiotics [29]. It was also found that $97.2 \%$ of antibiotic prescriptions at the $\mathrm{PH}$ and $97.7 \%$ at the DHs were first-line antibiotics. Beta-lactams were the most frequently prescribed for U5 (87.2\%). The STG recommendation on first-line antibiotics was implemented in those hospitals. A similar frequency of first-line antibiotic use was observed in Bahrain [33], and amoxicillin was frequently used to treat URTIs in primary care settings [34]. The present study found inappropriate doses and periods of antibiotic prescription, and the right doses were prescribed significantly more often at the $\mathrm{PH}(52.8 \%)$ than at the DHs (24.4\%). Thus, more attention is needed with respect to the prescription of appropriate antibiotic doses and prescription periods.

In many developing countries, antibiotic prescription for common cold is a public health concern [35-37]. Until recently, antibiotics were frequently used for common cold in Lao PDR. A study in 2004 demonstrated that antibiotics were prescribed for $41.0 \%$ of patients with non-pneumonia respiratory infections $(n=269)$ [38]. Prescription practices have been monitored by the government since 2013. At the beginning of the monitoring period, antibiotics were prescribed for almost $40 \%$ of common cold cases in public primary healthcare settings in Lao PDR. The health authority then urged practitioners to avoid such inappropriate practices. The present study revealed that antibiotics were prescribed for only $4.9 \%(8 / 164)$ of those with common cold. 
Table 7 Odds ratios (ORs) and 95\% confidence intervals (Cls) of antibiotic prescription for outpatients under 5 years of age with common cold or upper respiratory tract infection

\begin{tabular}{|c|c|c|c|}
\hline \multirow[t]{2}{*}{ Characteristics } & $A B$ prescribed & Unadjusted & Adjusted \\
\hline & $N(\%)$ & OR $(95 \% \mathrm{Cl})$ & OR $(95 \% \mathrm{Cl})$ \\
\hline \multicolumn{4}{|l|}{ Hospital } \\
\hline Provincial & $106(68.8)$ & 1 (Reference) & 1 (Reference) \\
\hline District & $299(70.8)$ & $1.10(0.73-1.64)$ & $0.73(0.26-2.07)$ \\
\hline \multicolumn{4}{|l|}{ Sex } \\
\hline Boys & $217(69.8)$ & 1 (Reference) & 1 (Reference) \\
\hline Girls & $188(70.9)$ & $1.06(0.74-1.51)$ & $1.04(0.44-2.46)$ \\
\hline \multicolumn{4}{|l|}{ Age group } \\
\hline 0 year & $79(62.2)$ & 1 (Reference) & 1 (Reference) \\
\hline 1 year & $99(68.3)$ & $1.30(0.79-2.16)$ & $0.55(0.15-2.06)$ \\
\hline 2 years & $102(75.6)$ & $1.88(1.10-3.19)$ & $0.72(0.18-2.81)$ \\
\hline 3 years & $74(75.5)$ & $1.87(1.04-3.36)$ & $0.40(0.93-1.71)$ \\
\hline 4 years & $51(71.8)$ & $1.54(0.82-2.91)$ & $0.30(0.06-1.41)$ \\
\hline \multicolumn{4}{|l|}{ Health insurances status } \\
\hline Covered by CBHI & $180(73.6)$ & 1 (Reference) & 1 (Reference) \\
\hline Covered by the others & $85(75.8)$ & $1.41(0.88-2.28)$ & $1.48(0.42-5.20)$ \\
\hline Not covered by health insurance & $141(62.1)$ & $0.53(0.37-0.76)$ & $1.37(0.49-3.82)$ \\
\hline \multicolumn{4}{|l|}{ Diagnosis } \\
\hline Common cold & $8(4.9)$ & 1 (Reference) & 1 (Reference) \\
\hline Pharyngitis & $341(96.0)$ & $474(195-1155)$ & $660(234-1856)$ \\
\hline Others & $56(98.3)$ & 1092 (133-8927) & $1567(177-13,876)$ \\
\hline
\end{tabular}

$\mathrm{CBHI}$ community-based health insurance

However, it was likely that U5 patients were given antibiotics before or after their visit to the health facilities, as antibiotics are sold in all private pharmacies without prescription.

There were several limitations to this study. First, the number of healthcare providers was limited, especially at the $\mathrm{PH}$, as the study focused on the medical staff in OPDs. Second, the relationship between the interviewees' responses to the questionnaire and their actual prescription practices was difficult to investigate. Third, the diagnosis was not confirmed by laboratory tests in all U5 patients, nor was the accuracy of the data recorded in the filing system in those health facilities. Finally, although this study was conducted in the largest province of Lao PDR, our sample may not represent the whole country.

In conclusion, the behaviors and prescription practices for U5 with common cold or URTI among healthcare providers at a $\mathrm{PH}$ and four $\mathrm{DHs}$ in Savannakhet Province were identified. They responded to follow the guideline for antibiotic prescription. While an appropriate number of generic first-line antibiotics from the EDL were prescribed, the prescribed doses and the periods of use were not appropriate.
With a view to further improve prescription practices, regulations by the Lao PDR Ministry of Health are necessary to allow for better control of antibiotic prescriptions, which would be crucial in decreasing antimicrobial resistance and improving treatment outcomes.

\section{Abbreviations \\ AAW: Antibiotic Awareness Week; ADR: Adverse drug reaction; Cl: Confidence interval; DH: District hospital; DTC: Drug and therapeutics committee; EDL: Essential drug list; INN: International non-proprietary name; Lao PDR: Lao People's Democratic Republic; MoH: Ministry of Health; OPD: Outpatient division; OR: Odds ratio; PH: Provincial hospital; RUD: Rational use of drug; STG: Standard Treatment Guideline; U5: Children under 5 years of age; URTI: Upper respiratory tract infections; WHO: World Health Organization}

\section{Acknowledgements}

We would like to express our sincere gratitude to the Director of the Savannakhet Provincial Health Department. We thank the staff at the Savannakhet Provincial Hospital, and the staff at the Songkhone, Champhone, Atsaphangthong and Xepon District Hospitals, for their active collaboration and participation in this study. We would like to express our sincere gratitude to the Director General of the Food and Drug Department and its staff, who supported this study.

\section{Funding}

This study did not receive specific grants from any funding agency in the public, commercial or non-profit sectors. 


\section{Availability of data and materials}

Depending on the request, data will be provided to the researchers after agreement of all authors.

\section{Authors' contributions}

BK designed this study, collected the data, and drafted the manuscript. MV $\mathrm{BP}, \mathrm{VL}$, and SI supported the data collection and interpretation of the results. TK, YMS, and EY critically revised the manuscript. NH designed the study and drafted and critically revised the manuscript. All authors read and approved the final manuscript.

\section{Ethics approval and consent to participate}

The study was approved by the National Ethics Committee for Health Research, Ministry of Health, Lao PDR (No.092/NECHR). The purpose of study was explained before the interview, and informed consent was the obtained from all participants.

\section{Consent for publication}

Not applicable.

\section{Competing interests}

The authors declare that they have no competing interests.

\section{Publisher's Note}

Springer Nature remains neutral with regard to jurisdictional claims in published maps and institutional affiliations.

\section{Author details}

${ }^{1}$ Department of Healthcare Administration, Nagoya University Graduate School of Medicine, 65 Tsurumai-Cho, Showa-Ku, Nagoya 466-8550, Japan. ${ }^{2}$ Food and Drug Department, Ministry of Health, Simuang road, Vientiane Capital, Lao People's Democratic Republic. ${ }^{3}$ Lao Tropical and Public Health Institute, Ministry of Health, Vientiane Capital, Lao People's Democratic Republic. ${ }^{4}$ National Health Insurance Bureau, Ministry of Health, Vientiane Capital, Lao People's Democratic Republic. ${ }^{5}$ Mittaphab Hospital, Phonsavang V, Chanthabouly D, Vientiane Capital, Lao People's Democratic Republic.

Received: 3 January 2019 Accepted: 13 February 2019

Published online: 28 February 2019

\section{References}

1. Costelloe C, Metcalfe C, Lovering A, Mant D, Hay AD. Effect of antibiotic prescribing in primary care on antimicrobial resistance in individual patients: systematic review and meta-analysis. BMJ. 2010;340:c2096.

2. Kousalya K, Thirumurugu S, Arumainayagam DC, Manavalan R, Vasantha J, Reddy CU. Antimicrobial resistance of bacterial agents of the upper respiratory tract in South Indian population. J Adv Pharm Technol Res. 2010:1:207-15.

3. World Health Organization. Antimicrobial resistance: global report on surveillance 2014. Geneva: World Health Organization; 2014.

4. Gentile I, Landolfo D, Buonomo AR, Crispo M, Iula VD, Minei G, et al. A survey on antibiotic therapy knowledge among physicians of a tertiary care and university hospital. Infez Med. 2015;23:12-7.

5. Arnold SR, To T, Mclsaac WJ, Wang EE. Antibiotic prescribing for upper respiratory tract infection: the importance of diagnostic uncertainty. J Pediatr. 2005;146:222-6.

6. Kumar R, Indira K, Rizvi A, Rizvi T, Jeyaseelan L. Antibiotic prescribing practices in primary and secondary health care facilities in Uttar Pradesh, India. J Clin Pharm Ther. 2008:33:625-34.

7. Ab Rahma N, Teng CL, Sivasampu S. Antibiotic prescribing in public and private practice: a cross-sectional study in primary care clinics in Malaysia. BMC Infect Dis. 2016;16:208.

8. Goossens H, Ferech M, Vander Stichele R, Elseviers M, ESAC Project Group. Outpatient antibiotic use in Europe and association with resistance: a crossnational database study. Lancet 2005;365(9459):579-587.

9. Albrich WC, Monnet DL, Harbarth S. Antibiotic selection pressure and resistance in Streptococcus pneumoniae and Streptococcus pyogenes Emerg Infect Dis. 2004;10:514-7.

10. Siddiqi S, Hamid S, Rafique G, Chaudhry SA, Ali N, Shahab S. Prescription practices of public and private health care providers in Attock District of Pakistan. Int J Health Plann Manag. 2002;17:23-40.
11. Ofori-Asenso R, Agyeman AA. A review of injection and antibiotic use at primary health care (public and private) centers in Africa. J Pharm Bioallied Sci. 2015;7:175-80

12. Sihavong A, Lundborg CS, Syhakhang L, Akkhavong K, Tomson G, Wahlstrom R. Antimicrobial self medication for reproductive tract infections in two provinces in Lao People's Democratic Republic. Sex Transm Infect. 2006;82:182-6.

13. Paphassarang C, Tomson G, Choprapawon C, Weerasuriya K. The Lao National Drug Policy: lesson along the journey. Lancet. 1995;345(8947):433-5.

14. Tomson G, Sterky G. Self-prescribing by way of pharmacies in three Asian developing countries. Lancet. 1986;2(8507):620-2.

15. World Health Organization. Success factors for women's and children's health: Lao PDR. Geneva: World Health Organization; 2015.

16. UN Inter-agency Group for Child Mortality Estimation. Level and trends in child mortality: United Nation Children's Fund; 2013. http://www. childmortality.org/files_v22/download/ Child\%20Mortality\%20Report\%202013.pdf. Accessed 20 Jan 2019.

17. Vang C, Tomson G, Kounnavong S, Southammavong T, Panyanouvong A, Johasson R, et al. Improving the performance of drug and therapeutics committees in hospital - a quasi-experimental study in Laos. Eur J Clin Pharmacol. 2006;62:57-63.

18. Ministry of Health, Lao PDR. The annual statistic update for health facility 2016. Vientiane Capital: Healthcare Department; Ministry of Health; 2016. (Lao language)

19. Ministry of Health, Lao PDR. Standard Treatment Guideline 2012. Vientiane Capital: Ministry of Health; 2012. (Lao language)

20. Prah J, Kizzie-Hayford J, Walker E, Ampofo-Asiama A. Antibiotic prescription pattern in a Ghanaian primary health care facility. Pan Afr Med J. 2017;28:214

21. Gasson J, Blockman M, Willems B. Antibiotic prescribing practice and adherence to guidelines in primary care in the Cape Town Metro District, South Africa. S Afr Med J. 2018;108:304-10.

22. Marom T, Bobrow M, Eviatar E, Oron Y, Ovnat Tamir S. Adherence to acute otitis media diagnosis and treatment guidelines among Israeli otolaryngologists. Int J Pediatr Otorhinolaryngol. 2017;95:63-8.

23. Tadesse BT, Asheley EA, Ongarello S, Havumaki J, Wijegoonewardena M, Gonzalez IJ, et al. Antimicrobial resistance in Africa: a systematic review. BMC Infect Dis. 2017;17:616.

24. Mbonye AK, Buregyeya E, Rutebemberwa E, Clarke SE, Lal S, Hansen KS, et al. Prescription for antibiotics at drug shops and strategies to improve quality of care and patient safety: a cross-sectional survey in private sector in Uganda. BMJ Open. 2016;6:e010632.

25. Tabemero P, Mayxay M, Culzoni MJ, Dwivedi P, Swamidoss I, Allan EL, et al. A repeat random survey of the prevalence of falsified and substandard antimalarials in the Lao PDR: a change for the better. Am J Trop Med Hyg. 2015;92(6 Suppl):95-104.

26. Mayxay M, Hansana V, Sengphilom B, Oulay L, Thammavongsa V, Somphet $V$, et al. Respiratory illness healthcare-seeking behavior assessment in Lao People's Democratic Republic (Laos). BMC Public Health. 2013;13:444.

27. Yevutsey S, Buabeng KO, Aikins M, Anto BP, Biritwum RB, Frimodt-Moller N, et al. Situation analysis of antibiotic use and resistance in Ghana: policy and regulation. BMC Public Health. 2017;17:896.

28. Miller E, Mackeigan LD, Rosser W, Marshman J. Effects of perceived patient demand on prescribing anti-infective drugs. CMAJ. 1999;161:139-42.

29. Quet F, Vlieghe E, Leyer C, Buisson Y, Newton PN, Naphayvong P, et al. Antibiotic prescription behaviours in Lao People's Democratic Republic: a knowledge, attitude and practice survey. Bull World Health Organ. 2015;93:219-27.

30. Vodicka TA, Tomson M, Lucas P, Heneghan C, Blair PS, Buckley DI, et al. Reducing antibiotic prescribing for children with respiratory tract infections in primary care a systematic review. Br J Gen Pract. 2013;63(612):e445-54.

31. Ofori-Asenso R, Brhlikova P, Pollock AM. Prescribing indicators at primary health care centers within the WHO African region: a systematic analysis (1995-2015). BMC Public Health. 2016;16:724.

32. Desalegn AA. Assessment of drug use patter using WHO prescribing indicators at Hawassa University teaching and referral hospital, South Ethiopia: a cross-sectional study. BMC Health Serv Res. 2013;13:170.

33. Senok AC, Ismaeel AY, Al-Qashar FA, Agab WA. Pattern of upper respiratory tract infections and physicians' antibiotic prescribing practices in Bahrain. Med Princ Pract. 2009;18:170-4.

34. Currie CJ, Berni E, Jenkins-Jones S, Poole CD, Ouwens M, Driessen S, et al. Antibiotic treatment failure in four common infections in UK primary care 1991-2012: longitudinal analysis. BMJ. 2014;349:95493. 
35. Sun Q, Dyar OJ, Zhao L, Tomson G, Nilsson LE, Grape M, et al. Overuse of antibiotics for common cold-attitudes and behaviors among doctors in rural areas of Shandong Province, China. BMC Pharmacol Toxicol. 2015;16:6.

36. Kamikawa J, Hernandes Granato CF, Bellei N. Viral aetiology of common colds of outpatient children at primary care level and the use of antibiotics. Mem Inst Oswaldo Cruz. 2015;110:884-9.

37. Jamhour A, El-Khei A, Salameh P, Hanna PA, Mansour H. Antibiotic knowledge, and self-medication practices in a developing country: a crosssectional study. Am J Infect Control. 2017:45:384-8.

38. Keohavong B, Syhakhang L, Sengaloundeth S, Nishimura A, Ito K. Rational use of drugs: prescribing and dispensing practices at public health facilities in Lao PDR. Pharmacoepidemiol Drug Saf. 2006;15:344-7.

Ready to submit your research? Choose BMC and benefit from:

- fast, convenient online submission

- thorough peer review by experienced researchers in your field

- rapid publication on acceptance

- support for research data, including large and complex data types

- gold Open Access which fosters wider collaboration and increased citations

- maximum visibility for your research: over $100 \mathrm{M}$ website views per year

At BMC, research is always in progress.

Learn more biomedcentral.com/submissions 